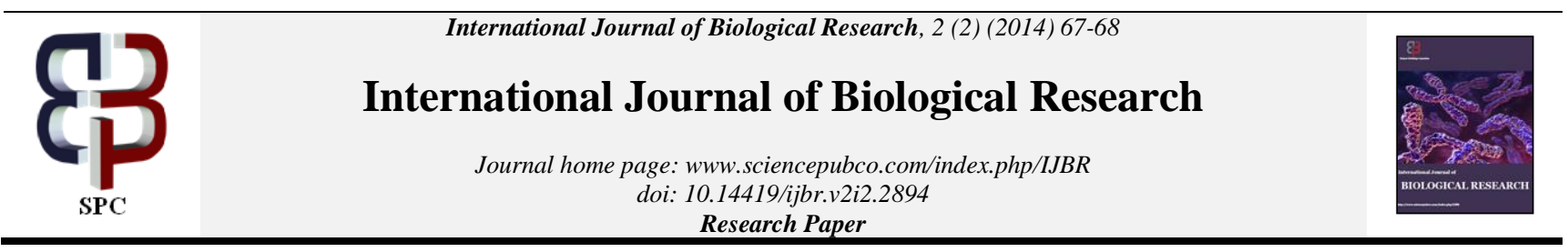

\title{
Effect of combined oral contraceptive on erythropoietin in female waster rats
}

\author{
Toryila J.E ${ }^{1 *}$, Amadi.K ${ }^{2}$, Odeh S.O ${ }^{2}$, Adelaiye A.B ${ }^{1}$,Mohammed A ${ }^{1}$,Achie L N ${ }^{1}$, Egesie U.G. ${ }^{2}$ \\ ${ }^{1}$ Human Physiology Department, Faculty of Medicine, ABU, Zaria \\ ${ }^{2}$ Human Physiology Department, Faculty of Medical Sciences, University of Jos, Jos \\ *Corresponding author E-mail: josephtoryila@ymail.com
}

\begin{abstract}
Erythropoietin (EPO), a 30kd glycoprotein is the primary hormonal regulator of erythropoiesis. erythropoietin promotes proliferation and differentiation of erythrocytes progenitor cells leading to production and release of mature reticulocytes expression and haemoglobin synthesis. Erythropoietin may also influence platelet production.

This study examined the effort of combined oral contraceptive (COCs) on serum erythropoietin level in female wistar rat. 80 female wistar rats weight $180 \mathrm{~g}-250 \mathrm{~g}$ were grouped into four (10 treated and 10 control rats). $0.66 \mathrm{~g} / \mathrm{body}$ weighgt COCs (DUOFEM) was given determined using ELISA kit. There was no significant increased or decreased in serum EPO in the treated groups compared to control groups ( $\mathrm{p}$ 0.119). Key word: combined oral contraceptives, erythropoietin, and female wistar rats.
\end{abstract}

Keywords: Combined Oral Contraceptives, Erythropoietin, Female Wistar Rats.

\section{Introduction}

Development of hormonal contraception marked a revolutionary step in social change that has improved the lives of women and families worldwide.

Combined oral contraceptives (COCs) are currently among the most common used drugs in developed countries.

Approximately 100 million women worldwide use oral contraceptives.

By reducing unintended pregnancies and abortions and facilitation of family planning, effective contraception provides both health and social benefits to mothers and their children (WHO, 2009; Vessy, 1995).

Erythropoietin (EPO) is a cytokine and a glycoprotein hormone that is essential for the proliferation viability and terminal differentiation of erythroid progenitor through erythropoietin receptor (EPOR) expression (Lodishetal, 1995, Wu et al, 1995).

Epo is produced mainly in the kidney and to some extend in the liver, brain and uterus. Epo is shown to act an non-haematopoietic cells such as central organs neverous system, the heart and the other organs and tissues resulting in tiuse protection (Rei et al, 200, Krantz, 1991). Epo has antiapoptopic, antioxidant and antiinflammatory effects.The effects of $\mathrm{COCs}$ on several haemorheological and haemostatic parameters has been reported (Akhigbe, et al, 2008).

There is growing concerns regarding the safety of the third generation coc used. There is little or no data available on the effects of coc on Erythropoietin in female wistar rats.

The study was aimed at determining the effect of cocs (Duofem) on Erythopoietin level in female wister rats.

\section{Materials and methods}

2.1. Animals
Eighty (80) female wistar rats aged 10-12 weeks weighing 180$250 \mathrm{~g}$ were used for the study. The animals were obtained at the Animal House of Human Physiology Department, Ahmadu Bello University, and Zaria. They were divided into four groups of 20 rats each comprising 10 treated and 10 control rats. They were placed in stainless steel cages ( 5 rats each). The rats were fed with normal rat chews (Vital Fees, Grand Cereal Oil Mills, Jos) and allowed water ad libitum. The treated groups received COC (DUOFEM) $0.66 \mathrm{mg} / \mathrm{kg}$ body weight intragrastically for 36,48 , 60 and 72 days in 5-day cycles (4-day treatment with a 1-day break). Experimental animals in this study were treated in accordance with the National Protection Laws of Animal Welfare.

\subsection{Drugs}

The COC drug used in this study is DUOFEM tablets $(0.03 \mathrm{mg}$ ethimylestradiol and $0.3 \mathrm{mg}$ norgestrel) manufactured by Pfizer, Belgium, packed and marketed by Society for Family Health Nigeria. Other reagents and chemicals used were of analytical grade and of the purest quality available commercially

Rat Erythropoietin ELISA kit ( Karmiya Biomedical company ) was used to measure rat serum Epo. The plasma was collected into plan bottles and centrifuged at $1000 \mathrm{xg}$ rpm for 10 minutes. The EPO rich plasma (400UL) was use for the EPO determination by ELISA Technique.

\section{Statistical analysis}

All data will be presented as mean \pm SEM. ANOVA was used to analyze the data generated. Statistical significance were based on $P$ value $\leq 0.05$. 


\section{Results}

There was an increase in EPO in group B (48 days). No significant increase in serum EPO level in the treated groups compared to the control $(\mathrm{P}<0.119)$. There was no significant decreased in serum EPO level in treated groups compare to controls.
Table 1: Effect of COC on Serum Erythropoietin in Female Wistar Rats.

\begin{tabular}{lll}
\hline Duration & Groups & Mean std \\
\hline \multirow{3}{*}{36 days } & A & $12.320 \pm 3.833$ \\
& Control & $10.560 \pm 1.638$ \\
48 days & B & $14.460 \pm 2.373$ \\
& Control & $11.920 \pm 1.277$ \\
60 days & C & $10.800 \pm 1.893$ \\
& Control & $11.180 \pm 1.959$ \\
72 days & D & $10.720 \pm 1.624$ \\
\hline
\end{tabular}

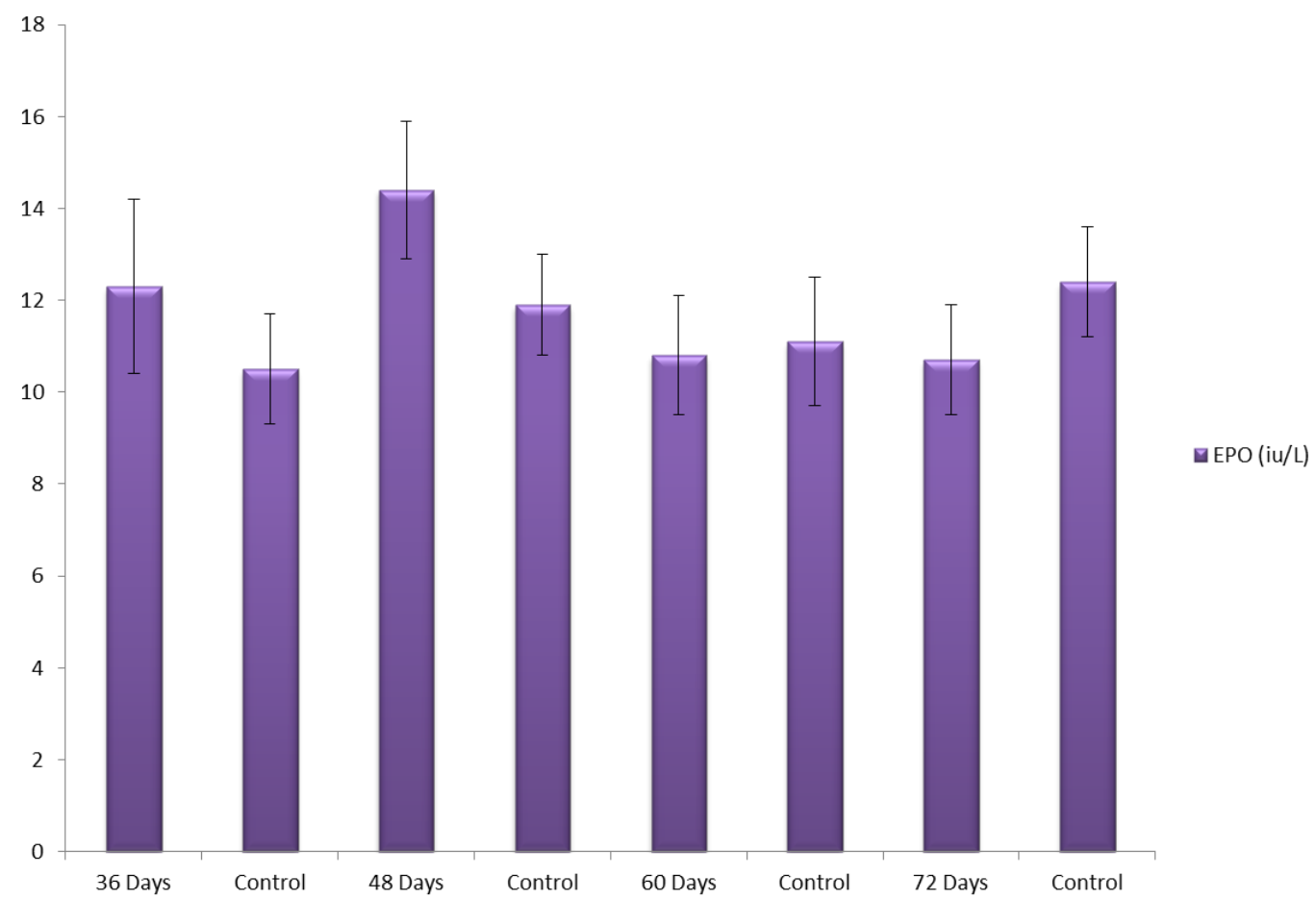

Fig. 1: The Effects of Combined Oral Contraceptives on EPO Count in Female Wistar Rats.

\section{Discussion}

The results show no significant increase in serum EPO in treated groups compare to control $(\mathrm{P}<0.119)$ this result is contrary to that of Prechile et al, 1972, in which they reported that estrogen inhibited the production of Erythropoietin in female rat.

The EPO showed an increase in group B of the treated groups, but did not achieve a statistical significance. It is possible that decrease in folic acid, vitamin B12. (,A Majid, 1982), and haemodilutory effect of estrogen may be the cause for decreased Red blood cell counts and pack cell volume in COCs users.

\section{Conclusion:}

The result of this study demonstrates that combined oral contraceptive (DUOFEM) has no significant effect on Erythropoietin production in female mister rats.

\section{References}

[1] A Majid Shojonia A (1982). Oral, contraceptive effects on folate and vitamin $\mathrm{B}_{12}$ metabolism. CMA Jornal, 126(1); 244-247.

[2] Krantz S. B (1991). Erythropoietin. Blood, 77:419-434

[3] Lodish H.F, Hilton D.J Klingmuller U, Watowich S.S, and Wu, H (1995). The erythropoietin receptor: Biogenesis dimerization and intfacellar signal transduction. Cold spring Harb syrup quant Biol, 60:93-104

[4] Monjok E., Andrea S. and John E. (2010). Contraceptive Practices in Nigeria. Centers for Disease control and Preventive (CDC): Family planning methods and practice (Africa $2^{\text {nd }}$ edition), Atlanta Georgia, Division of Reproductive Health, 2000 pp. 295 - 337.
[5] Prechile Cesare, Ira A Rappaport, Levido F.sasso, Mario Conclorelli and Albert S. Gordon (1972). The role of Estrogen in the regulation of Erythtopietin. Endocrinology;

[6] Rei Yokomizo, Sachiko Matsuzaki, Shigeka Vehara, Okamura (2002) Erythropoietin and Erythropoitin receptor expression in human endometrium through the mentral cycle.

[7] Vessy, M.P. (1995). Endometrial and ovarian cancer and oral contraceptives: findings in a large cohort study. British J. Canc., 71: 13401342.

[8] Wu H, Liu X, Jaenisch R, and lodish HF (1995) generation of committed erythoid BFU-E progenitors does not require erythropoietin or the erythropoietin receptor, cell 83:59-67

[9] WHO (2009). Hormonal contraception and liver diseases. Contraception, 80 : $325-326$ 